\title{
A new trapdoor spider species from the southern Coast Ranges of California (Mygalomorphae, Antrodiaetidae, Aliatypus coylei, sp. nov,), including consideration of mitochondrial phylogeographic structuring
}

\author{
MARSHAL HEDIN \& DAVE CARLSON \\ Department of Biology, San Diego State University, San Diego, CA 92182-4614, USA. E-mail: mhedin@sciences.sdsu.edu
}

\begin{abstract}
The trapdoor spider genus Aliatypus (Araneae, Mygalomorphae, Antrodiaetidae) includes 11 described species, 10 of which are endemic to California. Aliatypus species are known from most physiographic provinces in California, with the noticeable absence of described species from the southern Coast Ranges. This paper describes a new species (Aliatypus coylei, sp. nov.) that is shown to occur at more than 20 locations, most of which are in the southern Coast Ranges. This species is morphologically most similar to members of the A. erebus species group (A. erebus Coyle and A. torridus Coyle), but males differ from those of these latter species in several features. Female specimens are more difficult to distinguish from A. erebus and A. torridus, but can be easily separated using DNA characters. Collection of mitochondrial DNA sequence data from 21 sites shows that A. coylei is genetically very divergent from all described Aliatypus species, and reveals extreme population subdivision across the fragmented southern Coast Range landscape.
\end{abstract}

Key words: Population subdivision, spermathecal variation, California biodiversity, mygalomorph spider

\section{Introduction}

Mygalomorph spiders comprise a distinct clade of the Order Araneae, and include the trapdoor spiders, tarantulas, and kin (Raven 1985, Hedin \& Bond 2006). The mygalomorph spider fauna of California is one of the richest in the northern hemisphere, with the highest familial, generic, and species-diversity in the United States. Members of the families Antrodiaetidae (Coyle 1968, 1971, 1974; Coyle \& Icenogle 1994; Ramirez \& Chi 2004; Starrett \& Hedin 2007) and Cyrtaucheniidae (Bond et al. 2001; Bond \& Opell 2002; Stockman \& Bond 2007; Bond \& Stockman 2008) comprise the great bulk of this species diversity, and both families include genera that have radiated extensively and almost exclusively in California. An example is the antrodiaetid genus Aliatypus, which includes eleven described species, ten of which are endemic to California. Aliatypus are stocky, medium-sized (6-20 mm) grounddwelling spiders that cover their burrows with a thin, flap-like trapdoor (Fig. 1A, B). Most species in the genus occur in chaparral or mid-elevation forest habitats, although some species are also found in redwood forest or highelevation pine forests (Coyle 1974, Coyle \& Icenogle 1994).

When Coyle (1974) revised Aliatypus, he studied material from most physiographic provinces in California, but had few specimens available from the southern Coast Ranges. These ranges include a relatively low-lying set of north to south trending uplands, occupying a region from the San Francisco Bay south to the confluence with the Transverse Ranges at the southern terminus of the Central Valley (Fig. 1C; Schoenherr 1992). The southern Coast Ranges are bounded on the east by the Central Valley, and extend from here westward to the coast. The present-day highlands are potentially young ( 0.4 Ma, Page et al. 1998), and the region is still very geologically active, as it is bisected by the San Andreas fault. Older Pliocene seaways also once fragmented the region (Hall 2002; Bowersox 2005). Modern upland habitats are characterized by standard California Floristic Province vegetation, including chaparral, oak woodlands, and limited conifer woodlands. Higher western ranges (e.g., Santa Lucia Range) create a severe rain shadow and correspondingly steep environmental gradient, with desert-like eastern habitats (along the southwestern edge of the Central Valley) much drier than coastal habitats. Many endemic taxa have evolved in this 
region, including species of vertebrates (e.g., Jockusch et al. 2001; Davis et al. 2008; Parham \& Papenfuss 2009), plants (Stebbins \& Major 1965; Kraft et al. 2010), and arthropods (e.g., Platnick \& Ubick 2001; Ubick \& Briggs 2008; Bond \& Stockman 2008).

Coyle (1974) did not include definitive species records of Aliatypus from the southern Coast Ranges, but instead included three records simply labeled as "unidentifiable Aliatypus" (map 1 \& 4, Coyle 1974). Although not explicitly discussed, it is presumed that these records represent immature specimens, or locations with small numbers of female specimens only. Coyle (1974) did not provide collecting locality information for these specimens, and we have not examined this material. Based on on-going fieldwork conducted over the past 5-10 years, a moderate sample of fresh Aliatypus specimens from the southern Coast Ranges (and adjacent areas) has been accumulated. Most of these specimens represent a distinctive and previously undescribed species of Aliatypus, which we herein describe. We have also collected mitochondrial DNA sequence data from specimens representing most known records of this new species ( 21 geographic sites represented). These phylogeographic data reveal extreme mitochondrial population genetic structuring and high genetic divergences in the southern Coast Ranges. The phylogenetic placement of this new species is briefly considered here, but is treated more comprehensively in a separate paper (Satler et al. in review).

\section{Methods}

We searched appropriate microhabitats for spider burrows, and extracted spiders from burrows using entrenching shovels and smaller specialized digging tools. From any particular location we attempted to collect adult spiders (almost always females), but sometimes collected only immature spiders, or collected a mixture of adult and immature spiders. Immature spiders were provisionally identified to species based on association with identifiable adult specimens from the same location, or molecular clade association. Most spiders were transported live to the lab. For adults, 1-2 legs were removed from freshly-killed specimens and preserved for DNA analysis in 100\% EtOH at minus $80^{\circ} \mathrm{C}$; voucher specimens were stored separately in $80 \% \mathrm{EtOH}$ at minus $20^{\circ} \mathrm{C}$. Immature spiders were preserved as entire specimens in $100 \% \mathrm{EtOH}$ at minus $80^{\circ} \mathrm{C}$. All specimens were assigned a unique specimen identification number (MY number; see Table 1). Type specimens have been deposited at the California Academy of Sciences (CAS), San Francisco, California. Upon completion of our on-going studies, additional voucher specimens will be deposited at the CAS. Geographic location data was taken in the field using a global positioning system (GPS) device, and later verified/adjusted using Google Earth. A Google Earth kmz file of sampling sites is available as a Supplementary File.

Specimens were imaged using a Visionary Digital BK plus system (http://www.visionarydigital.com), including a Canon 40D digital camera, Infinity Optics Long Distance Microscope, P-51 camera controller, and FX2 lighting system. Individual images were combined into a composite image using Helicon Focus V5.1 software (http:// www.heliconsoft.com/heliconfocus.html), which was then edited using Adobe Photoshop CS3. Seminal receptacles (= spermathecae) were dissected from adult female specimens using fine forceps, immersed for 2-5 minutes in BioQuip specimen clearing fluid (www.bioquip.com) on a depression slide, then imaged directly in this fluid on slides. Other images were taken with specimens immersed in filtered $70 \% \mathrm{EtOH}$, using $\mathrm{KY}$ jelly or fine sand to secure specimens. All digital images have been deposited at Morphbank (www.morphbank.net; see Table 1).

Specimen measurements were taken from digital images using a calibrated ruler tool in Photoshop CS3. All appendage measurements were recorded from the left appendage, unless otherwise indicated. Measurements mirrored those of Coyle (1974), and only brief character descriptions are provided here. The reader is referred to Coyle (1974, figs 2-7) for more thorough character definitions: CL, CW—carapace length and width, PCL—length of pars cephalica; IFL, ITL, IML, ITarL—lengths of leg I segments (except for patella), viewed retrolaterally; IVFL, IVTL, IVML, IVTarL-lengths of leg IV segments (except for patella), viewed retrolaterally; PFL, PPL, PTLlengths of male pedipalp segments, viewed retrolaterally; PTT—maximum depth of male pedipalp; PTX - length of male pedipalp at maximum depth; PED—distance of base of embolus to tip of conductor; PCA—distance from PED line to edge of outer conductor sclerite; SL, SW-sternum length and width; PSS - minimum distance between posterior sigilla; PSL-maximum diameter of right posterior sigilla. All measurements are reported in millimeters (mm). 


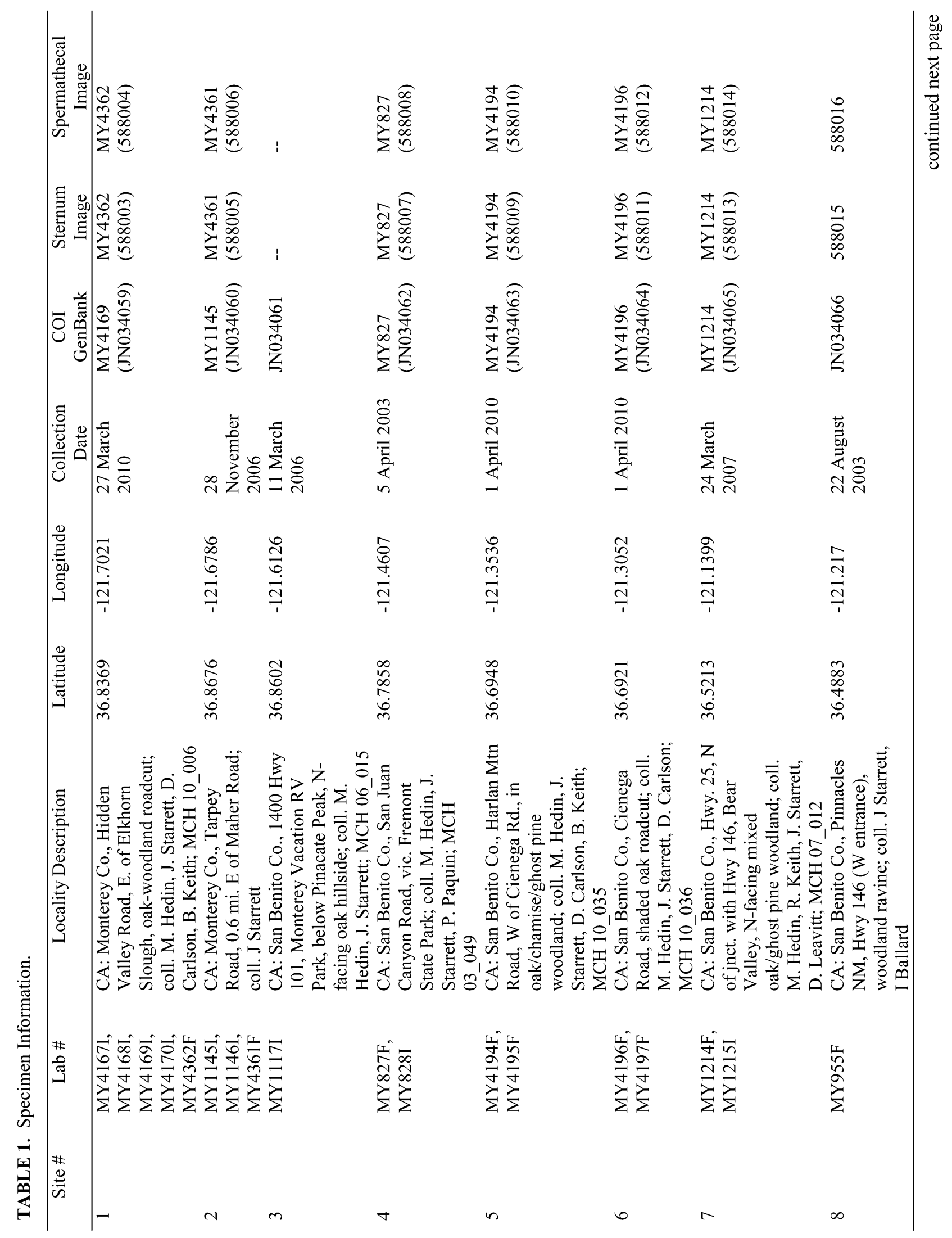




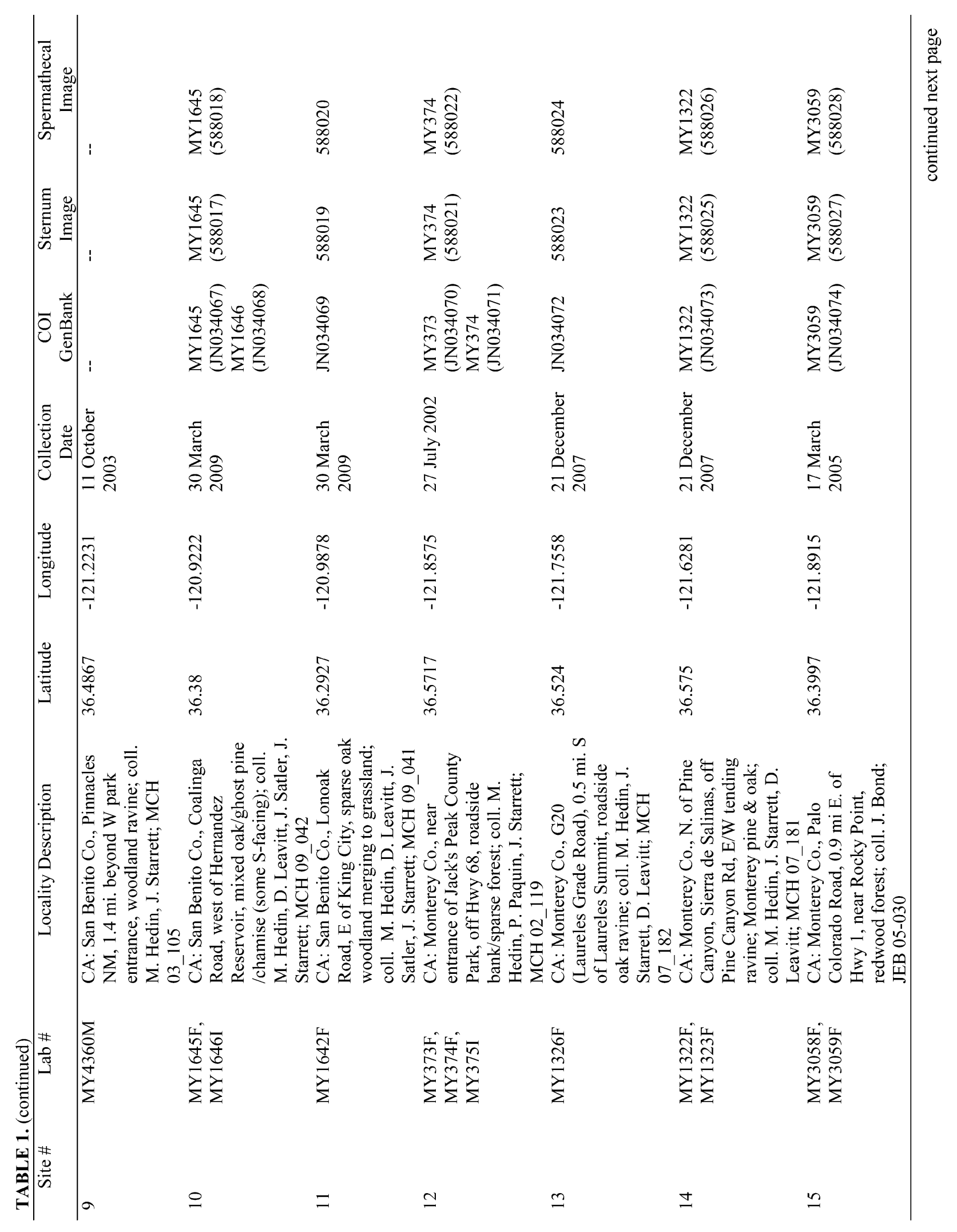




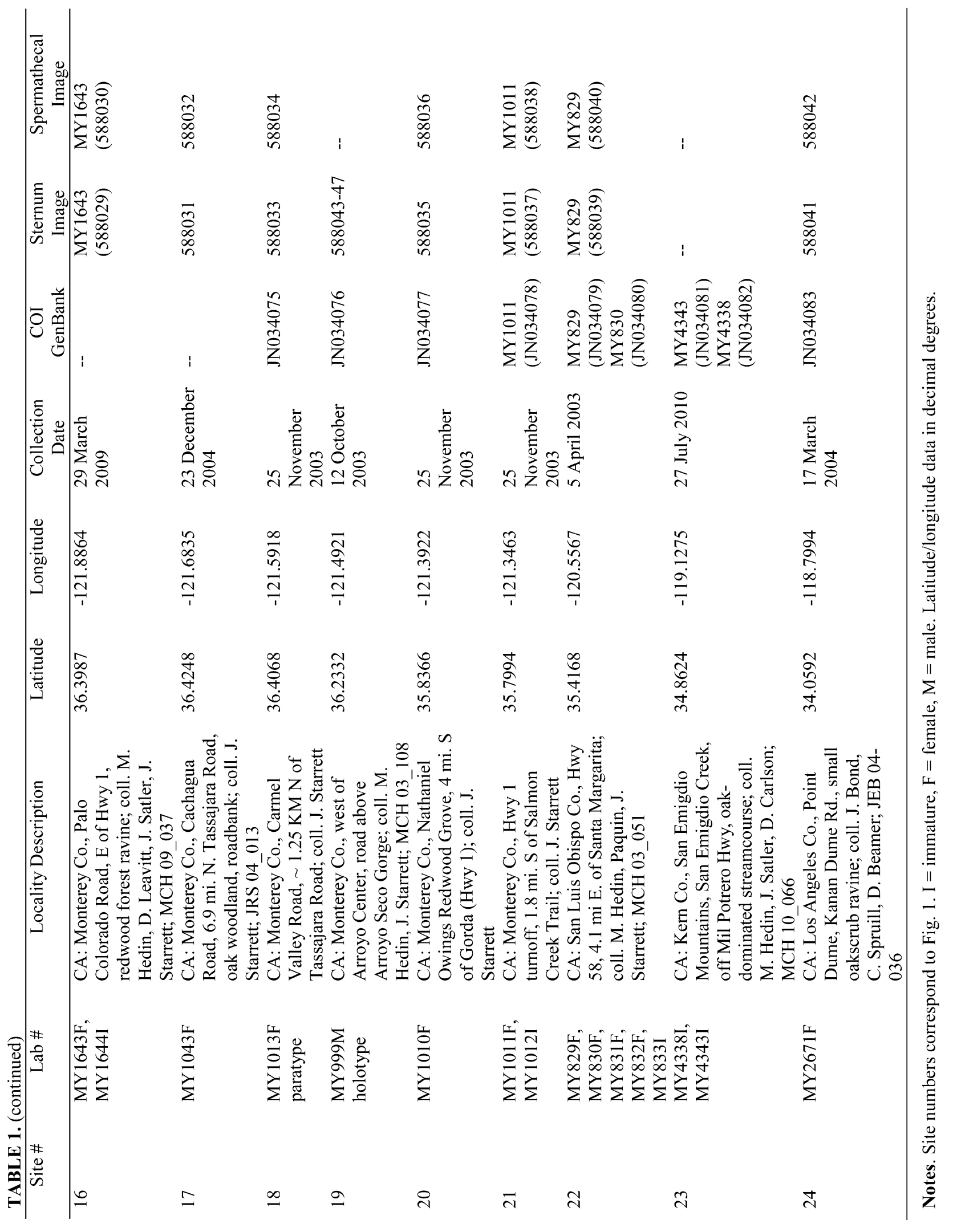


Genomic DNA was extracted from leg tissue using a DNAeasy kit (Qiagen). The polymerase chain reaction was used to amplify a fragment of the COI mitochondrial gene, using the C1-J-1751RIV (5'-GAGTTCCTGATATRGCTTTTCC-3') and C1-N-2776S (5'-GGATAATCAGAATANCGNCGAGG-3') primers reported in Starrett and Hedin (2007). PCR amplicons were directly sequenced in both directions, and contigs were assembled and edited using Sequencher 4.5 (Gene Codes Corporation, MI). Sequence data lacked indels, and were aligned manually in MacClade 4 (Maddison \& Maddison 2003). Genbank accession numbers of all newly generated sequences are provided in Table 1. A reference amino acid alignment can be retrieved using the Barcode of Life Data Systems (BOLD; www.boldsystems.org/), project code = CAMYG.

A Bayesian analysis of the aligned COI matrix was conducted using MrBayes 3.1.2 (Huelsenbeck \& Ronquist 2001, Ronquist \& Huelsenbeck 2003) on both partitioned (three partitions corresponding to codon positions) and unpartitioned data matrices. Models of DNA sequence evolution for data partitions were chosen using jModelTest 0.1.1 (Posada 2008); model likelihoods were calculated under three substitution schemes (JC, HKY, GTR) on a fixed BIONJ tree, allowing for unequal base frequencies and among-site rate variation. From these likelihood scores model selection was based on the Akaike Information Criterion (AIC). In partitioned analyses, partition parameters except for tree topology and branch lengths were estimated separately for individual partitions (using the unlink command in MrBayes). All Bayesian analyses consisted of two simultaneous independent runs, each consisting of four independent Metropolis-coupled Monte Carlo Markov chains. We used default hot and cold chain temperatures and swap frequencies, with uniform priors. As a convergence diagnostic, analyses were permitted to run until the standard deviation of split frequencies fell below 0.01 (Ronquist et al. 2005). The first $40 \%$ of trees were discarded as burn-in, with remaining trees used to reconstruct a 50\% majority rule consensus tree. Split frequencies were interpreted as posterior probabilities (pp) of clades. For purposes of tree rooting we used COI sequences representing all described Aliatypus taxa, and included multiple divergent sequences for species known to show geographic variation (data from Satler et al. in review).

\section{Systematics}

Family Antrodiaetidae Gertsch, in Comstock, 1940: 236 [urn:lsid:amnh.org:spiderfam:0002]

Genus Aliatypus Smith, 1908 [urn:Isid:amnh.org:spidergen:00006]

\section{Aliatypus coylei new species}

Figs 1-5

Type material. Male holotype from Arroyo Seco Gorge, W of Arroyo Center, Monterey County, California, $36.2332^{\circ} \mathrm{N}, 121.4921^{\circ} \mathrm{W}$, collected 12 October 2003, M. Hedin \& J. Starrett (MY999, CASENT9039430). COI GenBank JN034076, MorphBank images 588043-47. Female paratype from Carmel Valley Road, $1.25 \mathrm{~km} \mathrm{~N}$ of intersection with Tassajara Road, Monterey County, California, $36.4068^{\circ} \mathrm{N}, 121.5918^{\circ} \mathrm{W}$, collected 25 November 2003, J. Starrett (MY1013, CASENT9039431). COI GenBank JN034075, MorphBank images 588033-34.

Etymology. Patronym honoring mentor and friend Dr. Fred Coyle, in recognition of his rigorous and inspirational systematic research conducted on mygalomorph spiders, including the genus Aliatypus.

Diagnosis (Figs 2-4). Males are distinguished from those of other Aliatypus species by the following combination of characters-sternum like A. thompsoni Coyle and species of the A. erebus group, with relatively large, relatively closely-spaced posterior sternal sigilla (Coyle 1974, figs 60-64). This shape is best captured by the CL/PSL and SW/PSS ratios (Table 2). The shape of the A. coylei palpal tibia (banana-shaped) is unlike the above species, except for A. torridus (Coyle 1974, fig. 91). This shape is best captured by the PTX/PTL ratio (Table 2). Leg I segments of A. coylei males are relatively longer than A. torridus males (CL/IFL ratio, Table 2).

Females are distinguished from those of other Aliatypus species by the following combination of characterssternum most like species of the A. erebus group, with relatively large posterior sternal sigilla (Coyle 1974, figs 74-77), but not as closely spaced as those of A. thompsoni (see PSL/PSS ratio, Table 2). Aliatypus coylei also differs from A. thompsoni in having few ensiform macrosetae on metatarsus I, in possessing a thoracic pit, and in the shape of the seminal receptacles. Females of A. coylei are relatively short-legged, again like members of the A. ere- 
bus group (e.g., CL/IVTL ratio, Table 2), and possess similar-shaped seminal receptacles (Coyle 1974, figs 174194). Of the species in the A. erebus group, A. erebus and A. torridus are most likely to be confused with A. coylei (A. trophonius Coyle is diminutive, and A. plutonis Coyle is known only from far southern California). Although CL/PSL and SW/PSL ratios may be useful in distinguishing A. coylei from A. erebus and A. torridus (see Table 2), these morphological characters are unlikely to be strictly diagnostic. If genomic resources are available, the following amino acid changes in the COI reference alignment can be used to separate $A$. coylei from all members of the $A$. erebus group: position 15 (Phe in A. coylei, Ser in A. erebus group members), position 17 (Val, Glu), position 153 (Ile, Val), position 294 (Tyr, Asn), and position 310 (Cys, Asn).

TABLE 2. Comparison of informative character ratios in Aliatypus.

\begin{tabular}{|c|c|c|c|c|c|c|}
\hline Females & CL/IVTL & CL/PSS & CL/PSL & SW/PSS & SW/PSL & PSL/PSS \\
\hline A. californicus group & $2.3-2.9$ & $4.7-8.3$ & $12.1-33.2$ & $2.6-4.4$ & $6.5-16.2$ & $0.2-0.7$ \\
\hline A. aquilonius & $2.5-2.8$ & $4.4-6.8$ & $17.5-41$ & $2.3-3.4$ & $8.8-20$ & $0.1-0.4$ \\
\hline A. gulosus & $2.9-3.3$ & $4.8-6.3$ & $13.5-22.2$ & $2.6-3.4$ & $7.1-13.7$ & $0.2-0.4$ \\
\hline A. thompsoni & $2.6-3.1$ & $12.7-31.6$ & $6.5-10.9$ & $6.6-18.4$ & $3.3-5.7$ & $1.3-4.1$ \\
\hline A. erebus & $3.0-3.5$ & $7.7-14.7$ & $6.5-9.8$ & $4.3-8.5$ & $3.8-5.3$ & $0.8-2.0$ \\
\hline A. torridus & $3.1-3.4$ & $8-10$ & $8.3-10$ & $4.4-5.4$ & $4.6-5.4$ & $0.8-1.1$ \\
\hline A. coylei & 3.1 & 9.3 & 10.8 & 4.9 & 5.7 & 0.9 \\
\hline Males & CL/IFL & CL/PPL & PTT/PTL & PTX/PTL & CL/PSL & SW/PSS \\
\hline A. californicus group & $0.9-1.2$ & $1.3-1.9$ & $0.2-0.3$ & $0.7-0.8$ & $13.6-24.4$ & $2.2-4.3$ \\
\hline A. aquilonius & $0.9-1$ & $1.3-1.4$ & 0.2 & 0.7 & $24.3-34.1$ & $2.2-2.5$ \\
\hline A. gulosus & $0.9-1$ & $1.3-1.5$ & 0.2 & $0.4-0.5$ & $22.1-30.7$ & $2.2-2.9$ \\
\hline A. thompsoni & $0.8-0.9$ & $1.3-1.6$ & $0.2-0.3$ & $0.7-0.8$ & $8-10.7$ & $5.9-12.5$ \\
\hline A. erebus & $1.2-1.3$ & $1.6-2.0$ & 0.4 & $0.7-0.8$ & $8.8-13.4$ & $3.3-5.4$ \\
\hline A. torridus & $1-1.1$ & $1.6-1.9$ & 0.3 & $0.6-0.7$ & $10.3-14.4$ & $3.4-4.1$ \\
\hline A. coylei & 0.9 & 1.3 & 0.2 & 0.5 & 12.3 & 3.8 \\
\hline
\end{tabular}

Notes. Male and female data for species other than A. coylei are from Tables 1 \& 2 of Coyle (1974). All measurements in millimeters.

Holotype male (Fig. 2). Carapace 3.7 long, 3.2 wide, pars cephalica 2.2 long. Thoracic groove slightly oval, pit-like, anterior edge recurved. Cluster of postocular setae forming small backwards-pointing triangle. Leg I IFL 4.2, ITL 2.7, IML 2.6, ITarL 1.5. Dorsal setae on tibia and metatarsus mostly appressed, ventral ensiform macrosetae on tibia and metatarsus numerous, tibial dorsal macrosetae erect. Pedipalp PFL 4.7, PPL 2.8, PTL 3.9, PTX 2.0, PTT 0.7, PED 1.0, PCA 0.4. Tibia elongate, roughly banana-shaped, hirsute. Palpal bulb with loosely looped sperm reservoir, base of embolus relatively distant from base of inner conductor sclerite (ICS). Sternum SL 2.2, SW 1.9, posterior sternal sigilla moderately close (PSS 0.5), oval-shaped, faint. Abdomen tergite II large, tergite III subequal to tergite II, boundary indistinct; tergite I minute.

Paratype female (Figs 3-4). Carapace 6.5 long, 4.9 wide, pars cephalica 4.2 long. Thoracic groove pit-like, anterior edge slightly recurved. Cluster of postocular setae forming small backwards-pointing triangle. Chelicerae with row of 2 retrolateral macroteeth, 6 prolateral macroteeth, 7-8 intermediate microteeth. Leg I IFL 4.0, ITL 2.4, IML 1.8, ITarL 1.0, 11 ensiform macrosetae on metatarsus. Leg IV (right) IVFL 4.1, IVTL 2.1, IVML 3.2, IVTarL 1.4. Pedipalp tarsus with 7 ensiform macrosetae on prolateral surface, 3 ensiform macrosetae on retrolateral surface. Sternum SL 4.2, SW 3.4, posterior sternal sigilla well separated (PSS = 0.7), large (PSL = 0.6), oval-shaped. Seminal receptacles with relatively large bulbs as compared to stalk diameter, stalks short, with single bend.

Other records. The species is known from 20 other geographic locations, represented by 28 adult specimens (Table 1). Two other locations are represented only by immature specimens (sites 3 and 23, Table 1); DNA analyses indicate that these immatures are A. coylei specimens. 


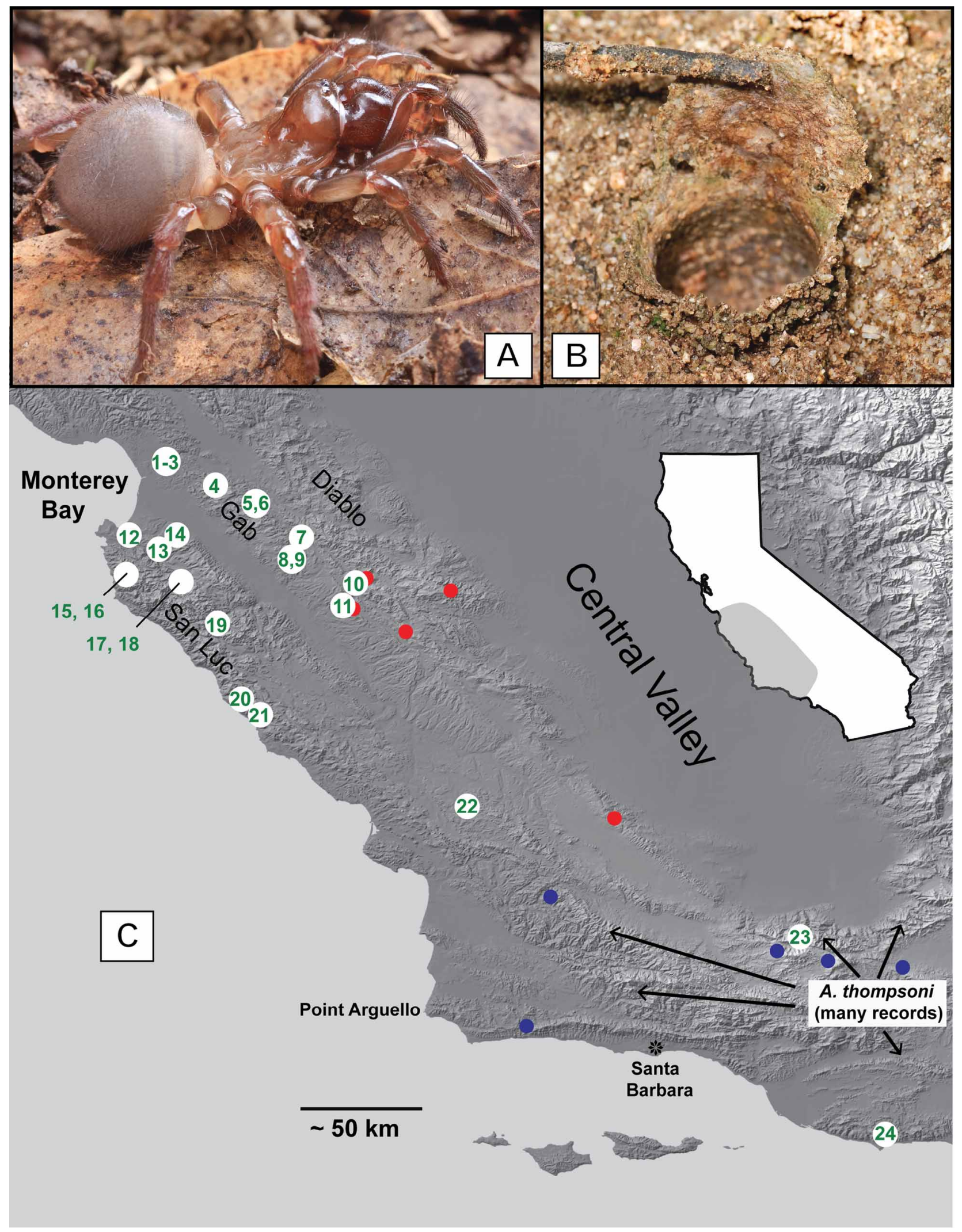

FIGURE 1. A) Adult female Aliatypus coylei (MY4194), Harlan Mountain Road, Gabilan Range, San Benito County; B) Aliatypus trapdoor, Harlan Mountain Road, Gabilan Range, San Benito County; C) Known distribution of Aliatypus coylei. Site numbers correspond to Table 1; some geographically adjacent sites are represented by a single white circle. Regional records of other Aliatypus species as follows: red dots = A. janus, blue dots = A. torridus (records from Coyle 1974, Coye \& Icenogle 1994; Satler et al. in review; personal observations). San Luc = Santa Lucia Range, Gab = Gabilan Range, Diablo = Diablo Range. 

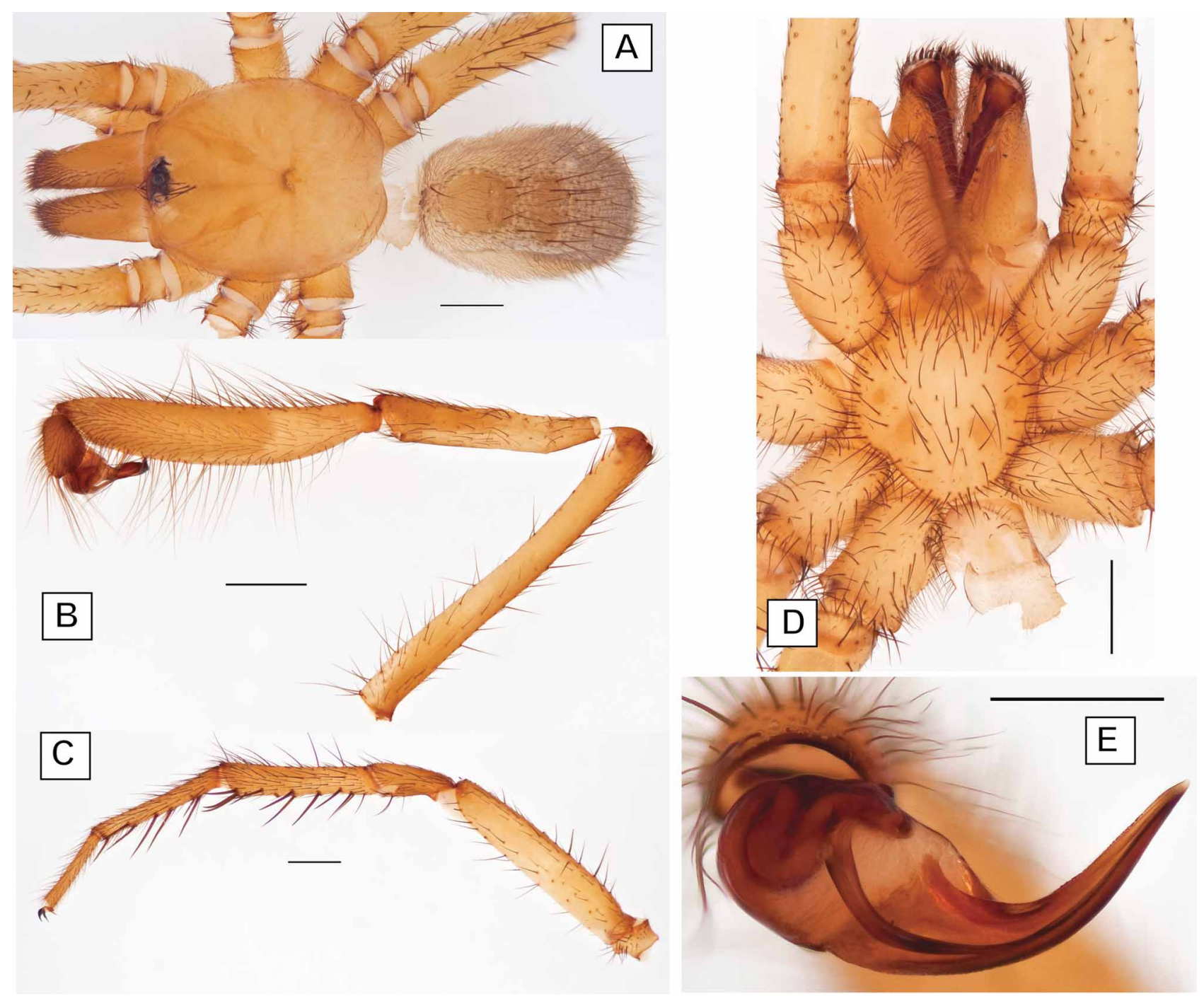

FIGURE 2. Male holotype, MY999 (CASENT9039430), W of Arroyo Center (site 19): A) carapace and abdomen, viewed dorsally, B) left pedipalp, viewed retrolaterally, C) left leg I, viewed retrolaterally, D) sternum and chelicerae, viewed ventrally, E) palpal bulb, viewed ventrally. Scale bar $A-D=1 \mathrm{~mm}, E=0.5 \mathrm{~mm}$.

Geographic variation. A male from site 9 (Table 1) is smaller-bodied than the holotype male, but otherwise conforms to the holotype in shape of palpal tibia, details of the bulb, and shape of sternal sigilla. Female specimens vary noticeably in shape of the seminal receptacles, although most possess relatively large bulbs, with short, narrow stalks. An exception is MY2671 from site 24 (Table 1), with seminal receptacles not unlike A. gulosus Coyle, with straight, short stalks leading to bulbs of only slightly larger diameter (Fig. 3L). Specimens from several sites include more stalk bends than the holotype female (e.g., Fig. 3E, G, J, K). The general characteristics of sternal sigilla morphology (large, fairly close together, diverging oblong shape) is similar among female specimens, with minor exceptions. For example, specimen MY374 from site 12 (Table 1) has relatively widely spaced, less elongate posterior sigilla (Fig. 4B). Several other females have irregular-shaped sigilla (e.g., Figs 4D, E).

Distribution. Most records are from the southern Coast Ranges, including the Gabilan, Diablo, Santa Lucia, and La Panza Ranges. Two isolated records are from further south in California, with a record from the Transverse Ranges (site 23, Table 1, Fig. 1), and a record from the Santa Monica Mountains (site 24, Table 1, Fig. 1).

Natural history. Consistent with the relatively broad geographic distribution of this species, populations have been found in several habitat types including coastal redwood forest, Monterey Pine forest, mixed Pinus sabiniana / Quercus woodland, and habitats dominated by Adenostemma / Arctostaphylos chaparral scrub. Essentially all collections are from more mesic microhabitats within these larger habitat types, including north-facing ravines, shaded 
banks, and shaded roadcuts. Burrows have been found on essentially vertical banks (e.g., sites 1, 5, 13, 15), but also on shallower slopes (e.g., sites 10, 12, 22). Many burrows were characterized by almost a complete absence of silk. Adult females have been collected throughout the year; two adult male specimens were collected from burrows in October (Table 1).
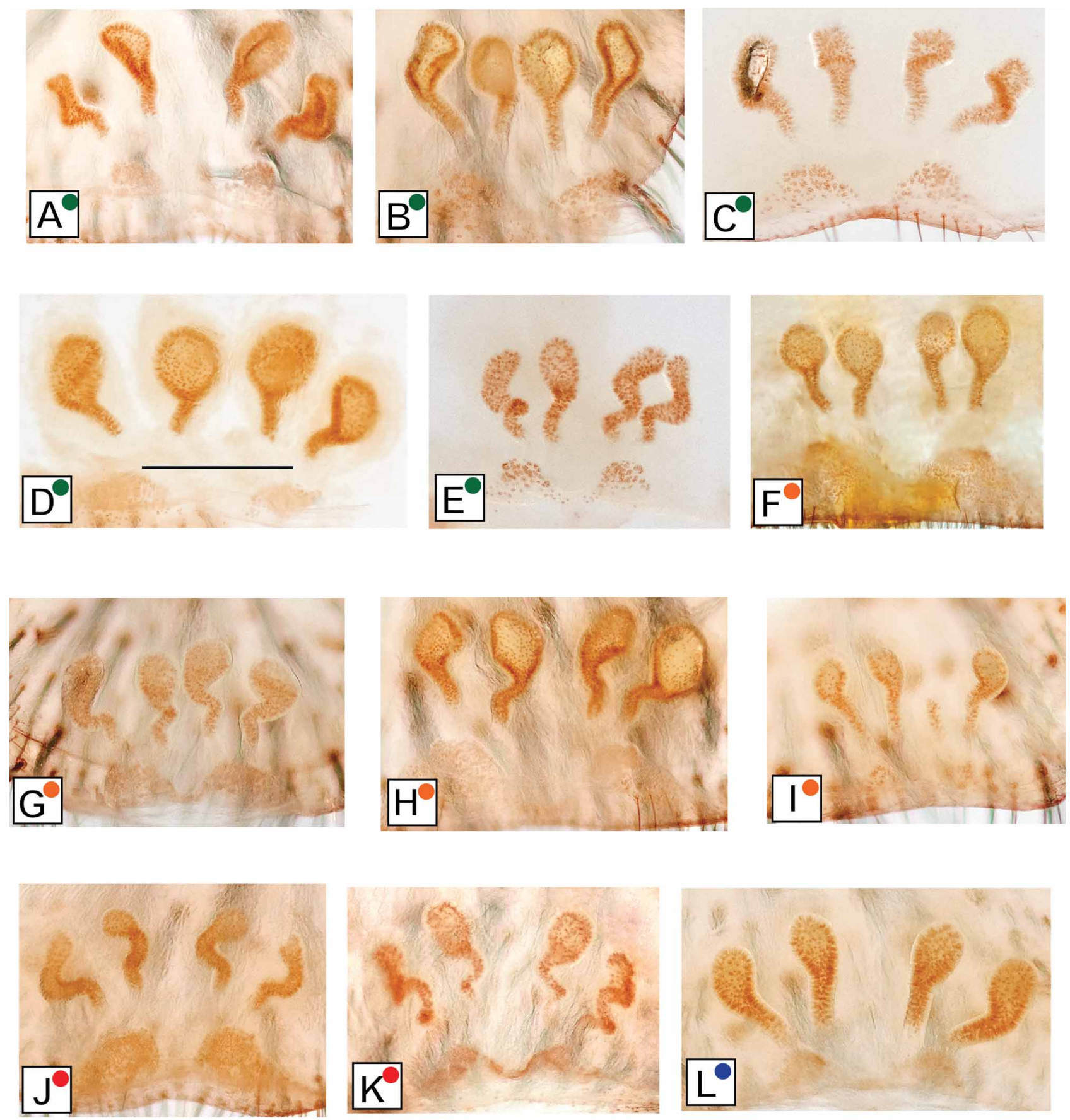

FIGURE 3. Female spermathecae, viewed ventrally: A) MY1013 (CASENT9039431) paratype female, Carmel Valley Road (site 18), B) MY1326, Laureles Grade Road (site 13), C) MY374, Jack’s Peak County Park (site 12), D) MY955, W of Pinnacles NM (site 8), E) MY3059, Palo Colorado Road (site 15), F) MY4194, Harlan Mtn Road (site 5), G) MY4362, Hidden Valley Road (site 1), H) MY1645, Coalinga Road (site 10), I) MY1642, Lonoak Road (site 11), J) MY829, E of Santa Margarita (site 22), K) MY1010, S of Gorda (site 20), L) MY2671, Kanan Dume Road (site 24). Colored dots correspond to genetic groups of Fig. 5. Site numbers correspond to Table 1 and Fig. 1C. Scale bar $=0.5 \mathrm{~mm}$. 

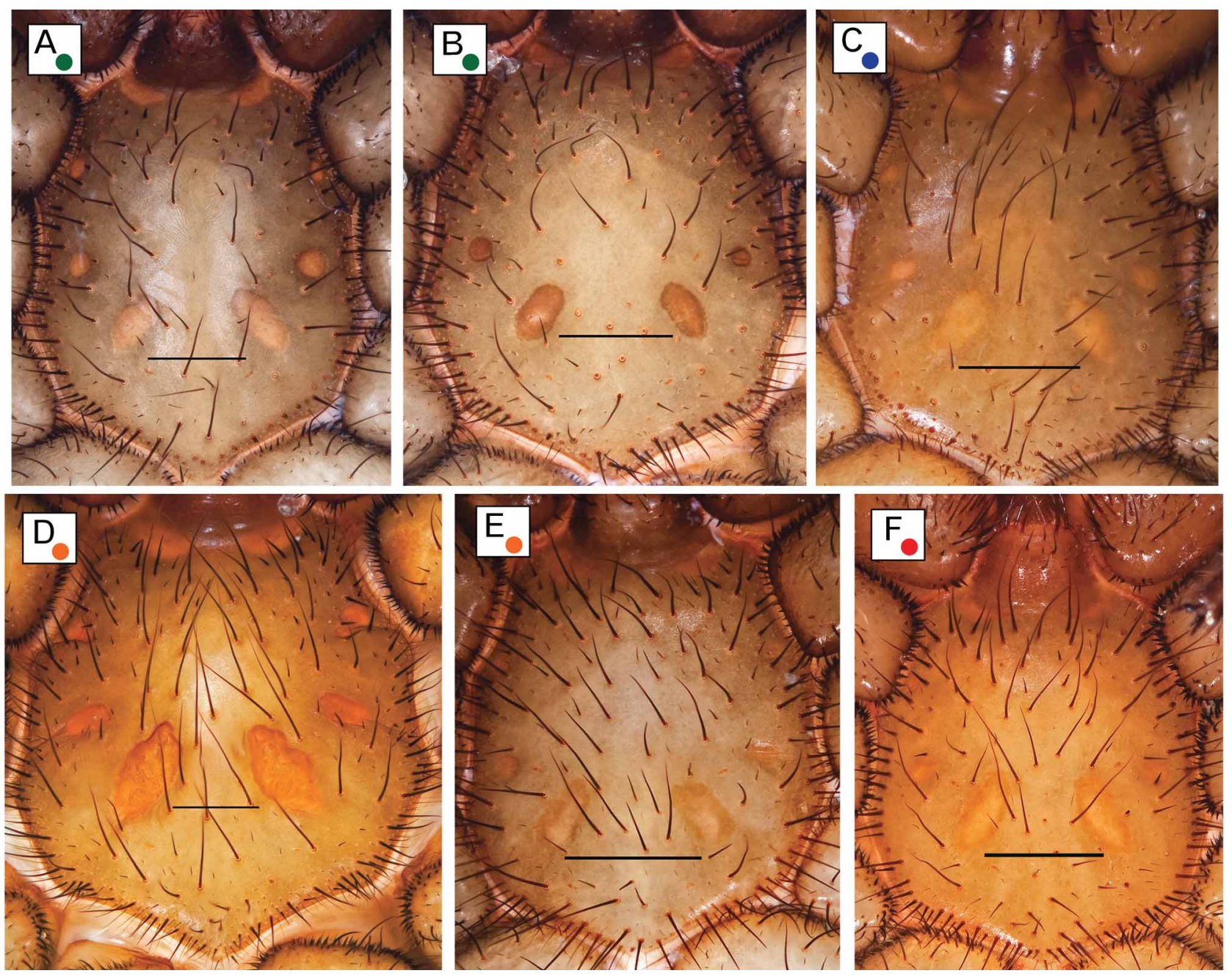

FIGURE 4. Female sternal sigilla, viewed ventrally: A) paratype female, MY1013, Carmel Valley Road (site 18), B) MY374, Jack's Peak County Park (site 12), C) MY2671, Kanan Dume Road (site 24), D) MY4194, Harlan Mtn Road (site 5), E) MY1642, Lonoak Road (site 11) F) MY829, E of Santa Margarita (site 22). Colored dots correspond to genetic groups of Fig. 5. Site numbers correspond to Table 1 and Fig. 1C. Scale bar $=1 \mathrm{~mm}$.

\section{Molecular phylogenetic results and discussion}

Phylogenetic Placement. Mitochondrial COI DNA sequences were generated from 19 adult A. coylei specimens collected from 17 geographic locations (Table 1). These data were combined with 21 COI sequences representing all other described Aliatypus species, and sequences from six immature Aliatypus specimens. Three immatures were collected syntopically with $A$. coylei adults (sites 1-2, 10; Table 1), and we expected them to fall within an $A$. coylei molecular clade. Three other immatures (sites 3, 23; Table 1) were identified based solely on molecular clade membership.

Partitioned and unpartitioned Bayesian analyses result in nearly identical tree topologies and very similar posterior probability values (Fig. 5). Results of the partitioned analysis are discussed below, with differences between analyses noted where applicable. We rooted the Bayesian majority rule consensus tree presuming an early-diverging placement of A. gulosus (following Coyle 1974, 1994; Satler et al. in review). Given this root placement, five other major Aliatypus lineages are recovered, including the multispecies A. californicus and A. erebus groups, and three phylogenetically isolated species: A. aquilonious Coyle, A. thompsoni, and A. coylei (Fig. 5A). A single topological difference within the $A$. californicus group distinguishes the unpartitioned and partitioned analyses at this deeper phylogenetic level. 

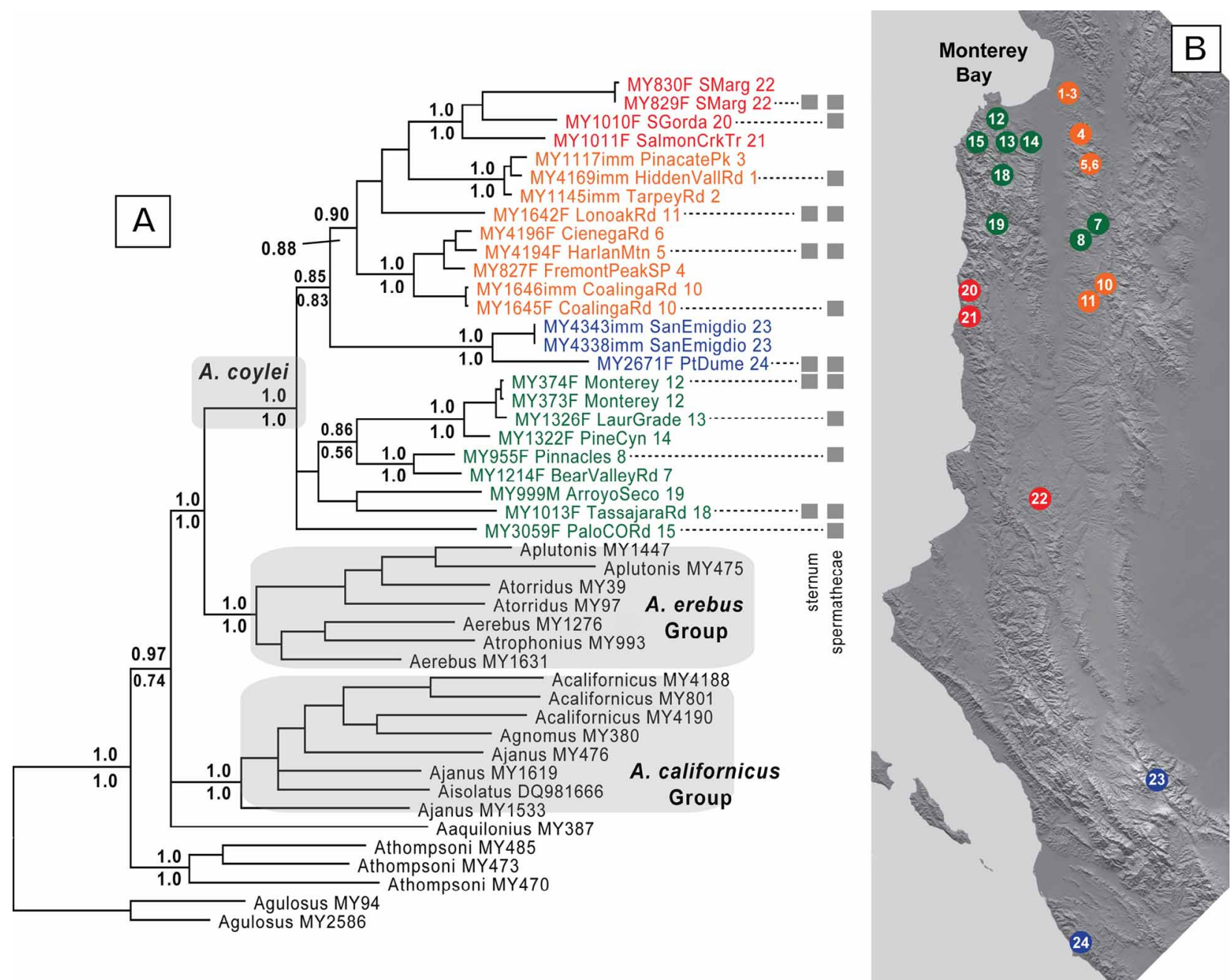

FIGURE 5. A) Majority-rule consensus phylogram resulting from partitioned Bayesian analysis. Aliatypus coylei haplotypes are labeled with specimen number, location abbreviation, and site number (corresponding to Fig. 1). Posterior probability values are shown for both partitioned (above branches) and unpartitioned (below branches) analyses. Samples with morphological images included in Figs 3 and 4 are highlighted. B) Geographic distribution of haplotype groupings. Site numbers correspond to Fig. 1.

Sequences from immature specimens from sites 3 and 23 are deeply nested within a well-supported $A$. coylei clade ( $\mathrm{pp}=1.0$ ). The A. coylei molecular clade is found to be sister to the A. erebus group on the COI gene tree (pp $=1.0$ ). A close molecular phylogenetic relationship between A. coylei and the A. erebus group agrees with the observed morphological similarities of these taxa (see Diagnosis).

Phylogeographic Patterns. Mitochondrial DNA sequence variation within A. coylei is characterized by extreme population genetic subdivision and high among-population divergence. There are no COI haplotypes shared among sampling sites, despite the close proximity of several sites. For example, site pairs 1-2, 5-6, 7-8, 12-13 and 20-21 (Fig. 1C) are separated by distances of 3-9 kilometers, but in all cases spiders from these sites carry different COI haplotypes (Kimura 2-parameter pairwise distances range from 1.1-7.8\%, Kimura 1980). This indicates that mutational differences in A. coylei mitochondrial genomes arise at very fine spatial scales, and that unique haplotypes are rarely exchanged among populations by female-based gene flow. These genetic patterns are consistent with the biology of Aliatypus spiders (microhabitat specialists, often found in aggregations at suitable sites, high female burrow fidelity; see Coyle 1971, 1974), and also consistent with patterns of fine-scale mitochondrial population structure found in other antrodiaetid taxa (Hendrixson \& Bond 2005, 2007; Starrett \& Hedin 2007).

The level of genetic divergence seen across the entire distribution of $A$. coyle $i$ is extreme (average K2P for all pairwise comparisons $=11.7 \%$ ), and this genetic variation is partitioned geographically (Fig. 5). One genetic group is found in the Sierra de Salinas and adjacent northern Santa Lucia Range (sites 12-19, Fig. 5), but also includes two sampled sites from the Gabilan Range (sites 7-8, Fig. 5). In unpartitioned analyses, this genetic group forms a weakly supported clade $(\mathrm{PP}<70)$ that includes basal sequences from site 15 . The Salinas-Gabilan genetic connec- 
tion is surprising given that these uplands are separated by the low elevation Salinas Valley. A second phylogeographic group includes two outlier southern sites (sites 23-24, Fig. 5), which are only moderately genetic divergent (pairwise $\mathrm{K} 2 \mathrm{P}=6.8 \%$ ) despite their large geographic separation. A final genetic group includes samples mostly from the Gabilan Range (sites 1-6, 10-11, Fig. 5), but also includes a clade of three "mid-latitude" sites (sites 2022, Fig. 5). Sites 20 and 21 are in the Santa Lucia Range, but are genetically divergent from more northerly Santa Lucia sites.

The phylogeographic structuring and very high genetic divergences observed in A. coylei suggest the possibility that this taxon may actually comprise a complex of closely related species. However, given evidence currently available, we prefer a single species hypothesis for three reasons. First, very high levels of intraspecific mitochondrial genetic divergence are common in antrodiaetid species-these divergences reflect the extremely dispersallimited biology of female spiders in these taxa. Second, patterns of geographic variation in spermathecal morphology do not coincide with genetic groupings (Figs 3,5), suggesting a lack of geographic subgroups that show coincident genetic and morphological divergence. Finally, DNA sequences from several independent nuclear gene regions reveal limited divergence within A. coylei (Satler et al. in review). For example, the average pairwise K2P distance between $28 \mathrm{~S}$ rDNA sequences representing all three mitochondrial groups (from sites 4, 8, 12, 15, 19, 24) is less than one percent (Satler et al. in review). This finding suggests that male-mediated nuclear gene flow may be acting as a cohesive force in this taxon, at least over evolutionary time. Similar contrasts in patterns of female- versus male-based genetic differentiation have been shown in dispersal-limited salamander species from the same geographic region (Jockusch \& Wake 2002). As for all taxonomic hypotheses, more data will ultimately be needed (e.g., more male specimens, data from additional nuclear genes) to rigorously test our single species hypothesis.

Distributional Limits \& Syntopy. While we still clearly have much to learn about the distribution of A. coylei, we hypothesize that our current sample likely captures the geographic boundaries of this species. The northern boundary appears to coincide with the "Pajaro Gap", a well-known biogeographic boundary found in many disparate taxa (Wake 1997). North of this gap, in the Santa Cruz Mountains, we find other Aliatypus species (Coyle 1974, Satler et al. in review). The eastern boundary of $A$. coylei should not extend beyond the western edge of the Central Valley, but whether A. coylei is actually found in the easternmost southern Coast Ranges (i.e., Diablo Range) remains to be determined. Most fieldwork conducted in this difficult-to-access area has resulted in the collection of A. janus Coyle (Fig. 1C), but A. coylei and A. janus are syntopic at sites 10 and 11 (Fig. 1C), indicating that they could also be syntopic further east. The southern and southeastern distributional limits of $A$. coylei remain obscure. The collection of $A$. coyle $i$ at sites 23 and 24 was surprising to us, as other Aliatypus species are abundant in this region (e.g., A. thompsoni, A. torridus, Coyle 1974; Satler et al. in review; unpublished observations). For example, we have collected A. thompsoni at nearly 100 sites in the central Transverse Ranges and Santa Ynez Mountains without encountering A. coylei, using the same search image applied further north. It seems that $A$. coylei exists in this southern region, but unpredictably and at low densities.

\section{Acknowledgements}

We thank the many people who helped to collect specimens, including Ian Ballard, Chad Spruill, Dave Beamer, Lars Hedin, Pierre Paquin, Bob Keith, Dean Leavitt and Jason Bond. Jordan Satler and Jim Starrett in particular provided many key specimens. Some fieldwork was supported by National Science Foundation grant DEB 0108575 (to M. Hedin and Jason Bond). Many land owners allowed us to collect on their property. Comments from Amber Beavis, Bob Keith, Robert Raven, and members of the Hedin lab helped to improve the manuscript.

\section{Literature cited}

Bond, J.E. \& Opell, B.D. (2002) Phylogeny and taxonomy of the genera of south-western North American Euctenizinae trapdoor spiders and their relatives (Araneae: Mygalomorphae: Cyrtaucheniidae). Zoological Journal of the Linnean Society, $136,487-534$.

Bond, J.E. \& Stockman, A.K. (2008) An integrative method for delimiting cohesion species: Finding the population: species interface in a group of Californian trapdoor spiders with extreme genetic divergence and geographic structuring. Systematic Biology, 57, 628-646.

Bond, J.E., Hedin, M.C., Ramirez, M.G. \& Opell, B.D. (2001) Deep molecular divergence in the absence of morphological and ecological change in the Californian coastal dune endemic trapdoor spider Aptostichus simus. Molecular Ecology, 10, 899-910.

Bowersox, J.R. (2005) Reassessment of extinction patterns of Pliocene molluscs from California and environmental forcing of 
extinction in the San Joaquin Basin. Paleogeography, Paleoclimatology, Paleoecology, 221, 55-82.

Coyle, F.A. (1968) The mygalomorph spider genus Atypoides (Araneae: Antrodiaetidae). Psyche, 75, 157-194.

Coyle, F.A. (1971) Systematics and natural history of the mygalomorph spider genus Antrodiaetus and related genera (Araneae: Antrodiaetidae). Bulletin of the Museum of Comparative Zoology, 141, 269-402.

Coyle, F.A. (1974) Systematics of the trapdoor spider genus Aliatypus (Araneae: Antrodiaetidae). Psyche, 81, 431-500.

Coyle, F.A. (1994) Cladistic analysis of the species of the trapdoor spider genus Aliatypus (Araneae, Antrodiaetidae). The Journal of Arachnology, 22, 218-224.

Coyle, F.A. \& Icenogle, W.R. (1994) Natural history of the Californian trapdoor spider genus Aliatypus (Araneae, Antrodiaetidae). The Journal of Arachnology, 22, 225-255.

Davis, E.B., Koo, M.S., Conroy, C., Patton, J.L. \& Moritz, C. (2008) The California hotspots project: identifying regions of rapid diversification of mammals. Molecular Ecology, 17, 120-138.

Gertsch, W.J. (1940) in Comstock, J. H. 1940. The Spider Book, revised and edited by W. J. Gertsch. Cornell Univ. Press, Ithaca, $\mathrm{xi}+727 \mathrm{pp}$.

Hall, C.A.J. (2002) Nearshore marine paleoclimate regions, increasing zoogeographic provinciality, molluscan extinctions, and paleoshorelines, California: late Oligocene (27 Ma) to late Pliocene (2.5 Ma). Geological Society America, Special Paper, 357, v-489.

Hedin, M. \& Bond, J.E. (2006) Molecular phylogenetics of the spider Infraorder Mygalomorphae using nuclear rRNA genes (18S and 28S): Conflict and agreement with the current system of classification. Molecular Phylogenetics and Evolution, 41, 454-471.

Hendrixson, B.E. \& Bond, J.E. (2005) Testing species boundaries in the Antrodiaetus unicolor complex (Araneae: Mygalomorphae: Antrodiaetidae): "paraphyly" and cryptic diversity. Molecular Phylogenetics and Evolution, 36, 405-416.

Hendrixson, B.E. \& Bond, J.E. (2007) Molecular phylogeny and biogeography of an ancient Holarctic lineage of mygalomorph spiders (Araneae: Antrodiaetidae: Antrodiaetus). Molecular Phylogenetics and Evolution, 42, 738-755.

Huelsenbeck, J.P. \& Ronquist, F. (2001) MRBAYES: Bayesian inference of phylogeny. Bioinformatics, 17, 754-755.

Jockusch, E.L. \& Wake, D.B. (2002) Falling apart and merging: diversification of slender salamanders (Plethodontidae: Batrachoseps) in the American West. Biological Journal of the Linnean Society, 76, 361-391.

Jockusch, E.L., Yanev, K.P. \& Wake, D.B. (2001) Molecular phylogenetic analysis of slender salamanders, genus Batrachoseps (Amphibia: Pletodontidae), from central coastal California with descriptions of four new species. Herpetological Monographs, 15, 54-99.

Kimura, M. (1980) A simple method for estimating evolutionary rates of base substitutions through comparative studies of nucleotide sequences. Journal of Molecular Evolution, 16, 111-120.

Kraft, N.J.B., Baldwin, B.G. \& Ackerly, D.D. (2010) Range size, taxon age and hotspots of neoendemism in the California flora. Diversity and Distributions, 16, 403-413.

Maddison, D.R. \& Maddison, W.P. (2003) MacClade 4.06: Analysis of phylogeny and character evolution. Version 4.06. Sinauer Associates, Sunderland, MA, USA.

Page, B.M., Thompson, G.A. \& Coleman, R.G. (1998) Late Cenozoic tectonics of the central and southern Coast Ranges of California. GSA Bulletin, 110, 846-876.

Parham, J.F. \& Papenfuss, T.J. (2009) High genetic diversity among fossorial lizard populations (Anniella pulchra) in a rapidly developing landscape (Central California). Conservation Genetics 10, 169-176.

Platnick, N.I. \& Ubick, D. (2001) A revision of the North America spiders of the new genus Socalchemmis (Araneae, Tengellidae). American Museum Novitates, 3339, 1-25.

Posada, D. (2008) jModelTest: Phylogenetic model averaging. Molecular Biology and Evolution, 25, 1253-1256.

Ramirez, M. \& Chi, B. (2004) Cryptic speciation, genetic diversity and gene flow in the California turret spider Antrodiaetus riversi (Araneae: Antrodiaetidae). Biological Journal of the Linnean Society, 82, 27-37.

Raven, R.J. (1985) The spider infraorder Mygalomorphae (Araneae): cladistics and systematics. Bulletin of the American Museum of Natural History, 182, 1-180.

Ronquist, F. \& Huelsenbeck, J.P. (2003) MRBAYES 3: Bayesian phylogenetic inference under mixed models. Bioinformatics, $19,1572-1574$.

Ronquist, F., Huelsenbeck, J.P. \& van der Mark, P. (2005) MrBayes 3.1 Manual, Draft 5/26/2005, online at http:// mrbayes.csit.fsu.edu/manual.php (last accessed 4 February, 2011).

Satler, J., Starrett, J., Hayashi, C. \& Hedin, M. (2011) Inferring species trees from gene trees in a radiation of California trapdoor spiders (Araneae, Antrodiaetidae, Aliatypus). In review.

Schoenherr, A.A. (1992) A Natural History of California, University of California Press.

Starrett, J. \& Hedin, M. (2007) Multilocus genealogies reveal multiple cryptic species and biogeographical complexity in the California turret spider Antrodiaetus riversi (Mygalomorphae, Antrodiaetidae). Molecular Ecology, 16, 583-604.

Stebbins, G.L. \& Major, J. (1965) Endemism and speciation in the California flora. Ecological Monographs, 35, 1-35.

Stockman, A.K. \& Bond, J.E. (2007) Delimiting cohesion species: extreme population structure and the role of ecological interchangeability. Molecular Ecology, 16, 3374-3392.

Swofford, D.L. (2002) PAUP*: Phylogenetic Analysis Using Parsimony (*and Other Methods). Version 4. Sinauer Associates, Sunderland, Massachusetts.

Ubick, D. \& Briggs, T.S. (2008) The harvestman family Phalangodidae 6. Revision of the Sitalcina complex (Opiliones, Laniatores). Proceedings of the California Academy of Sciences, 59, 1-108.

Wake, D. (1997) Incipient species formation in salamanders of the Ensatina complex. Proceedings of the National Academy of Sciences, USA, 94, 7761-7767. 